\title{
Watta Satta:
}

\section{Bride Exchange and Women's Welfare in Rural Pakistan}

\author{
Hanan G. Jacoby and Ghazala Mansuri*
}

\begin{abstract}
In a setting where husbands wield considerable coercive power, forms of marriage should adapt to protect the interests of women and their families. This paper studies the pervasive marriage custom of watta satta in rural Pakistan, a bride exchange between families coupled with a mutual threat of retaliation. We show that watta satta may be a mechanism to coordinate the actions of two sets of in-laws, each of whom wish to restrain their son-in-laws but who only have the ability to restrain their sons. Our empirical results support this view. The likelihood of marital inefficiency, as measured by estrangement, domestic abuse, and wife's mental health, is significantly lower in watta satta arrangements as compared to conventional marriages, but only after properly accounting for selection.
\end{abstract}

World Bank Policy Research Working Paper 4126, February 2007

The Policy Research Working Paper Series disseminates the findings of work in progress to encourage the exchange of ideas about development issues. An objective of the series is to get the findings out quickly, even if the presentations are less than fully polished. The papers carry the names of the authors and should be cited accordingly. The findings, interpretations, and conclusions expressed in this paper are entirely those of the authors. They do not necessarily represent the view of the World Bank, its Executive Directors, or the countries they represent. Policy Research Working Papers are available online at http:/lecon.worldbank.org.

*Development Research Group, World Bank, 1818 H St. NW, Washington, DC 20433. Jacoby email: hjacoby@worldbank.org; Mansuri email: gmansuri@worldbank.org. We have benefited from comments received at the 2005 NEUDC (Providence) and BREAD (Cambridge) conferences, as well as the 2006 Mini-Conference on Development (Quebec City). 
"[Watta satta] means that you will give a daughter and receive the same in return. It also implies that if our daughter will be in pain, we will treat your daughter the same way." (woman from Badeen, Sindh $)^{1}$

\section{Introduction}

Marriage is perhaps the epitome of an incomplete contract. Its terms can never be fully specified ex-ante or enforced ex-post. A vast body of literature has thus highlighted the role of post-marital bargaining in determining intrahousehold allocations (seminal papers include McElroy and Horney, 1981; Manser and Brown, 1980; and Lundberg and Pollack 1993). In traditional societies, where women's formal legal rights are often weak, divorce is strongly stigmatized, and there is a high premium on female virginity, bargaining power can shift radically in favor of the man once the woman commits herself to marriage. This fact should have implications for the form of the marriage 'contract'; in particular, its ex-ante provisions should reflect the interests of the wife and her family in deterring or mitigating ex-post malfeasance on the part of the husband.

In this paper, we argue that exchange marriage in rural Pakistan can play just such a role. Bride exchange, known locally as watta satta (literally, 'give-take'), usually involves the simultaneous marriage of a brother-sister pair from two households. Remarkably, watta satta accounts for about a third of all marriages in rural Pakistan. ${ }^{2}$ Watta satta is more than just an exchange of daughters, however; it also establishes the shadow of mutual threat across the marriages. As the watta-bride quoted above expresses so succinctly, a husband who 'mistreats' his wife in this arrangement can expect his brother-in-law to retaliate in-kind against his sister.

We shall show that such reciprocal threats operating across marriages can be credible and may, consequently, prevent inefficient marital outcomes. Husbands generally have coercive power over their wives, through various forms of physical and emotional intimidation. In virilocal societies, this power is heightened by the wife's residence in

\footnotetext{
${ }^{1}$ All of the quotations in this paper are from field interviews conducted as part of a qualitative survey undertaken in selected villages covered by the 2004-05 Pakistan Rural Household Survey.

${ }^{2}$ Similar marriage patterns prevail in south India, whereas in north India sibling exchange marriage is generally disapproved of (Mencher and Goldberg, 1967; Karve, 1993; Trautmann, 1993). Nevertheless, exchange marriage appears to have been common among Hindus in the Punjab, at least formerly (Rose, 1908). Outside south Asia, exchange marriage has been documented in parts of China (Zhang, 2000). Early anthropological accounts of exchange marriage in west Africa also mention the 'retaliatory' motive emphasized in this paper, but here it is typically in reaction to a wife's 'malfeasance' (such as leaving her husband) that her brother's marriage is dissolved.(Bohannan, 1949; Meek, 1936).
} 
her in-laws' household, making it costly for her natal family to continually monitor her treatment. The exercise of coercion is not without cost, though, both to the wife directly and possibly to her family. Family honor is particularly susceptible to publicly observable acts, like the temporary return of the wife to her natal home. Parents may be willing to restrain their son from such destructive (albeit privately rational) behavior, but only if they could also be assured that the in-laws of their daughter would restrain their son in the same way. An exchange marriage, we will argue, essentially solves this coordination problem.

This theory of exchange marriage has several linkages to past work. La Ferrara (2003), in the context of credit transactions, shows how the family or kin-group fills the void left by the absence of legally enforceable contracts. Like us, La Ferrara explicitly models the way in which families punish deviations from a particular equilibrium, although the mechanisms are quite distinct in the two cases. Zhang and Chan (1999) are perhaps the first to suggest that the form of the marriage contract might reflect ex-post bargaining considerations. Parents, they argue, choose the size of their daughter's dowry ex-ante taking into account its effect on the value of her threatpoint, although in their setting marital bargaining always leads to efficient outcomes. Our main concern is with institutions that may emerge to deter inefficiency within marriage. In this respect, our work fits into a broader program that seeks to rationalize institutional design in light of commitment failures (see, e.g., North and Weingast, 1989; Greif, 1993; and especially Williamson, 1983, who also emphasizes the value of mutual hostage-taking).

The key implication of the theory is that, all else equal, inefficiency is less likely to occur in watta satta marriages than in conventional marriages. To test this hypothesis, we have collected a large data set that provides unusual detail on marriage customs and the status of women in rural Pakistan. In particular, we examine measures of marital discord: estrangement, domestic violence, and the wife's mental health, outcomes associated with the exercise of coercion on the part of the husband.

Our main empirical challenge is to deal with systematic selection into exchange marriages. Watta satta may, for example, tend to be chosen by low status or traditional households, in which women are treated more poorly on average irrespective of marriage type. If so, the institution might appear detrimental to women, thus seeming to vindicate popular Pakistani press accounts that lump watta satta together with other more egregious practices like child-marriage and honor-killings. Fortunately, we have a plausible instrument. Exchange marriage opportunities are limited by the presence of age and sex 
appropriate siblings; a watta-bride normally must have an available brother, preferably an older one by not too many years. Thus, the likelihood of watta satta increases in the number of close older brothers a woman has and declines in the number of sisters who may be in competition with her for these brothers. Of course, the sibling sex composition of a woman's natal family may be a reflection of the degree of her parents' boy-preference, which may, in turn, be correlated with the woman's own marital outcomes. Our identification strategy, discussed below, deals with this potential correlation.

After taking into account selection bias, the empirical results conform to our theoretical priors. Women in watta satta marriages have substantially and significantly lower probabilities of marital estrangement, domestic abuse, and major depressive episodes. The latter two findings in particular suggest that the peculiar institution of watta satta - a bride exchange coupled with a mutual threat of reciprocity - protects the welfare of women in rural Pakistan.

The rest of the paper is organized as follows. Section 2 describes the nature of watta satta and its relationship to marital discord in rural Pakistan. Section 3 then sketches a model illustrating the potential advantage of exchange marriage. Our empirical strategy is laid out in section 4 , followed by the results in section 5 . Section 6 summarizes the findings and concludes.

\section{Marriage and its Discontents in Rural Pakistan}

\subsection{Data}

The data used throughout this paper are from the second round of the Pakistan Rural Household Survey (PRHS II) undertaken in 2004-05. Our sample consists of about 3100 married woman age 15-40 in households randomly sampled from 171 villages in the two most populous provinces, Punjab and Sindh (the sample is broadly representative of these provinces). Detailed modules on marriage, domestic abuse, and mental health, among many other topics, were administered to each respondent meeting the above criteria, including those very few who were divorced or separated from their husbands.

The main objective of the mental health module was to assess major depression (MD) using an instrument adapted from the CIDI-SF survey of the World Health Organization. In the development of the questionnaire, training of the enumerators, and conducting of the field validations, we were assisted by experienced psychiatrists from the Institute of Psychiatry in Rawalpindi General Hospital. Given the sensitivity of the mental health 
module as well as of the other topics, women were interviewed in strict privacy by carefully trained female enumerators. As a consequence, response rates were extremely high. Moreover, the patterns of domestic abuse and MD that we find are very much in line with comparable data from south Asia and elsewhere.

\section{$2.2 \quad$ Watta Satta}

Because marriage in rural Pakistan is often arranged by parents well in advance of the actual ceremony, sometimes when the principals are still children, care must be exercised in categorizing watta satta relationships. An intended exchange marriage may not yet be operational at the time of the survey. In particular, if there is a sufficiently large age gap between the two couples involved in the watta satta, the second couple may not yet be married and, possibly, not even born! There are also cases, though very few, where the second couple is no longer married or living together at the time of the survey. We define a watta satta marriage as one in which both of the counterpart couples are currently married; otherwise, the reciprocal threats may not yet be, or may be no longer, operative. Whereas $43 \%$ of our sample women report that their marriage involved a bride exchange, $5.5 \%$ of the women are in wattas in which the counterpart couple has not yet married and $1.5 \%$ are in wattas in which the counterpart couple are no longer living together. ${ }^{3}$ This gives us an incidence of watta satta, strictly defined, of $36 \%$.

The vast majority of watta satta marriages (94\%) involve at least one brother-sister pair, and most (72\%) involve a brother-sister pair on both sides. The second most popular watta satta arrangement ( $16 \%)$, but still far less prevalent than brother-sister, is when at least one of the households (but rarely both) contributes an uncle-niece pair. Various other combinations occur as well, though none in significant numbers.

Marriage in rural Pakistan is characterized by a remarkable degree of endogamy. Nearly two-thirds of the women in our sample $(62 \%)$ have married men from the same village or a neighboring village, and only $20 \%$ have married outside the tehsil (sub-district). Even more striking is the extent of marriage within clan and caste: $77 \%$ of women in our sample have married a blood relative, mostly first-cousins with a preference for the paternal side ${ }^{4} 13 \%$ have married someone unrelated by blood but within the same caste

\footnotetext{
${ }^{3}$ There is no difference in the rate of divorce or separation (around $1.5 \%$ ) between the women in watta satta marriages and those in conventional marriages.

${ }^{4}$ Edlund (1999), for one, argues that cousin-marriage may be motivated by the desire to have in-laws of comparable status. Since land is usually divided equally among male heirs in Pakistan, and land confers status in a rural society, paternal cousins would be particularly well-matched in terms of both wealth and
} 
(zaat/biraderi); leaving just $10 \%$ of marriages exogamous with respect to clan and caste. Exchange marriage clearly facilitates endogamy by forging a double union across the same two families, but this does not seem to be the sole motivation for the arrangement in rural Pakistan. The incidence of watta satta in our sample (using the looser definition, which is more appropriate here) is $48 \%$ among women married to a blood relative, $28 \%$ among those married to an unrelated member of the same caste, but is still $23 \%$ among those having no blood or caste affiliation to their husband.

Exchange marriage might also serve as a mechanism for alleviating the financial burden of dowry. If dowry is principally a price for husbands (a view recently challenged by Botticini and Siow, 2003), the advantage of marrying ones daughter into ones son's wife's family is clear: it establishes a double-coincidence of wants, obviating the need to exchange money or wealth at the time of the joint marriage. In rural Pakistan, however, dowry values are relatively modest (median in our sample is $12 \%$ of median annual nondurable household consumption expenditures) and dowry assets are generally controlled by the woman herself rather than delivered directly to her in-laws (see World Bank, 2005). Moreover, in an analysis reported elsewhere (World Bank, 2005), we find no evidence that the value of dowries are lower in watta satta marriages. ${ }^{5}$ In sum, then, it would appear that exchange marriage is not driven mainly by considerations of dowry avoidance.

\subsection{Measuring Marital Discord}

As already mentioned, the vast majority of women in rural Pakistan live in close geographical proximity to their natal families. Consequently, the parents' home is, for most, a potential exile from their husband's household, albeit not a costless one. ${ }^{6}$ In our sample, $19 \%$ of women report that they had returned to their natal home at least once during their marriage due to an estrangement from their husband. These periods of estrangement are generally short, the modal duration being less than a month.

Estrangement is probably the clearest expression of the intensity of marital discord. Given the considerable psychic penalties, it is also not a decision taken lightly:

"Sometimes I thought of going back to my parents but then I did not want

status.

${ }^{5}$ Since low status households are more likely to undertake exchange marriages (see below), and would tend to provide smaller dowries, the OLS estimates reported by us in the World Bank study are likely to be biased in favor of a negative watta satta effect. Despite this, we cannot reject the null of no effect.

${ }^{6}$ In the Indian context studied by Bloch and Rao (2002), where village exogamy is the norm, a wife's return to her natal household is an even more drastic and unlikely course of action. 
to worry them. Sometimes when my in-laws quarrel with me and bad mouth me, I think that I will not tell this to my parents. Some women go to their natal home, but they have to come back eventually or the people of the village taunt them. It degrades the women." (woman from Mirpurkhas, Sindh)

"In our family, it is a tradition that women live in their husband's home and do not leave it... When I got married, my father told me that if my in-laws will be happy with me, he would consider me a wise person. The very words he used to say were that he would consider the daughter astute who would not return from her home due to any conflict. This was inculcated in our minds since childhood." (woman from Faisalabad, Punjab)

One fifth of the women in our sample report having been physically hurt by their husbands in at least one of following ways: pushed, hit, slapped, kicked, thrown, choked, burned or attacked with a weapon. Arguably, domestic violence as conventionally measured is a less direct indicator of marital inefficiency than estrangement. For one thing, husbands can be physically abusive outside the context of marital discord, such as when intoxicated. Moreover, in a social setting where violence against women is unexceptional and, therefore, tolerated to a degree, there is likely to be a threshold level below which domestic abuse remains hidden from parents, in-laws, and society at large. By contrast, marital strife that has precipitated an estrangement can no longer be concealed. Estrangement must, therefore, occur only after violence or emotional intimidation has become intolerable. Not surprisingly, though, there is a positive correlation between domestic abuse and estrangement; $47 \%$ of women who report having been physically harmed by their husbands also said they had been estranged from him at some point in the marriage, as compared to just $11 \%$ for women who have never been abused.

Our final indicator of marital inefficiency is women's mental health. Based on our diagnostic instrument, $23 \%$ of sample women suffer from major depression. Since MD is likely to capture the cumulative effects of the whole array of emotional and/or physical intimidation deployed against the woman by her husband and his family, it may provide a more complete picture of marital discord than our measure of domestic abuse. On the other hand, depression could be triggered by stresses outside of marriage, or might be altogether unrelated to stress. At any rate, we view these two indicators of women's welfare as complementary. In our sample, $38 \%$ of women with major depression also reported domestic abuse, as compared to $20 \%$ of non-depressed women, so their overlap is far from perfect. 


\subsection{Reciprocity and Concordance}

While reciprocity appears to be a key element in Pakistani exchange marriage, it is a knife that cuts both ways. The upside is deterrence:

"...[W]e do such marriages because if we will give our daughter without it, she might get harmed. We do watta satta so that our daughter remains secure." (woman from Badeen, Sindh)

The downside is that, when deterrence fails, violence in one marriage may spill over into the counterpart marriage:

"Yes, my marriage involves watta satta agreement... When my husband beats me, I go and tell my mother and sister. My brother feels bad about this and then he beats his wife to take revenge... There are many fights in our family because of this... I do feel that it is the women who are being beaten in both families. (woman from Mirpurkhas, Sindh)

The empirical question that we address in section 5 is whether watta satta averts more marital strife than it causes.

Before doing so, however, we consider a more basic question: Are mutual threats of retaliation actually carried out, as the qualitative evidence seems to indicate? To answer this question we would need data on marital discord experienced by pairs of sister-inlaws, some of which are involved in watta satta arrangements and some of which are in conventional marriages. We could then check whether there is a higher degree of concordance in marital discord across watta satta sister-in-law pairs as compared to conventional sister-in-law pairs. Such a finding would be suggestive of retaliation.

By design, our data set does include a large subsample of matched sister-in-laws. Households containing sister-in-laws (age 15-40) of all currently married women in the base sample were tracked down and interviewed as long as they resided in the same village (which is likely given the high degree of village endogamy already noted). In total, we are able to match over 500 sister-in-law pairs of whom $55 \%$ are linked by watta satta. ${ }^{7}$

\footnotetext{
${ }^{7}$ Because watta satta marriages tend to be more village endogamous than conventional marriages, they are over-represented in the matched sister-in-law sample relative to the full sample.
} 
To test for differences in concordance across marriage types, while controlling for variables such as the duration of marriage, we use a simple regression-based procedure. Let $y_{i}$ be an outcome, such as estrangement, for woman $i$ and $y_{i}^{s}$ be the same outcome for her sister-in-law. Consider a regression of the form

$$
y_{i}=\theta_{0}+\theta_{1} y_{i}^{s}+\theta_{2} W S_{i}+\theta_{3} W S_{i} y_{i}^{s}+\theta_{4} \Delta m_{i}+\eta_{i}
$$

where $W S_{i}$ is an indicator for whether the sister-in-laws are linked in a watta satta arrangement and $\Delta m_{i}$ is the difference in their number of years married. The least-squares estimate of $\theta_{3}$ converges in probability to

$$
\frac{\operatorname{Cov}\left(y_{i}, y_{i}^{s} \mid W S_{i}=1, \Delta m_{i}\right)}{\operatorname{Var}\left(y_{i}^{s} \mid W S_{i}=1, \Delta m_{i}\right)}-\frac{\operatorname{Cov}\left(y_{i}, y_{i}^{s} \mid W S_{i}=0, \Delta m_{i}\right)}{\operatorname{Var}\left(y_{i}^{s} \mid W S_{i}=0, \Delta m_{i}\right)} .
$$

The null hypothesis of equal concordance can thus be rejected against the one-sided alternative of greater concordance for watta satta sister-in-laws if the estimate of $\theta_{3}$ is significantly greater than zero.

Table 1 reports the results of this test for different marital outcomes. For estrangement, there is strong evidence that watta satta sister-in-laws are more concordant than conventional sister-in-laws. This finding is consistent with our field interviews: Typically, a husband in a watta satta marriage responds to his sister-counterpart's estrangement by sending his own wife back to her natal home.

One might worry, however, that this concordance test is picking up some other source of positive correlation in the outcomes of watta satta sister-in-law pairs that has nothing to do with retaliation. In particular, we know that watta satta is more prevalent among couples who are blood relatives (see subsection 2.2). When first-cousins, for example, marry in a brother-sister watta, the resulting sister-in-laws and their husbands are necessarily first-cousins as well. For this reason alone, their marital outcomes may be more highly correlated as compared to unrelated sister-in-laws. To check whether this is driving our results, the second row of Table 1 re-runs the concordance test controlling for whether the spouses (and by implication the sister-in-laws) are blood relatives. We do find that sister-in-laws related by blood are more concordant on estrangement than unrelated ones ( $p$-value $=0.037)$, but the result of the watta satta concordance test is not appreciably affected, so the suggestion of a retaliatory response remains.

If estrangement of watta satta sister-in-laws is indeed linked by reciprocity, then the length of their most recent period of estrangement should also be more closely related than 
it is for conventionally married sister-in-laws. This can be examined using the sample of 50 sister-in-law pairs (30 of which are watta satta) wherein both women have experienced at least one episode of marital estrangement. In the third row of Table 1, we see that log estrangement duration is significantly more correlated for the watta satta sister-inlaws. Again, this finding is consistent with operative reciprocity among the watta satta marriages in our sample.

Finally, we report on the concordance results for domestic abuse and depression. Although these two marital outcomes are also more correlated among watta satta sister-inlaws than among conventional sister-in-laws, the differences are not statistically significant. These weak findings relative to those for estrangement can be explained by the conceptual difference between the indicators already discussed. Unlike estrangement, which is an extreme and visible act, domestic abuse is more hidden and, at the same time, is often viewed as normal or inevitable. A retaliatory response may thus be initiated only if violence exceeds a certain threshold. Similarly, mental depression is not a discrete incident that can easily be reciprocated in-kind. Nevertheless, failure to find positive evidence of reciprocity here does not imply that women in watta satta marriages are not better off along these dimensions, as the analysis of section 5 will show.

\section{A Model of Exchange Marriage}

To rationalize exchange marriage coupled with retaliatory threats, we sketch a model that takes into account the incentives of the principal actors: husbands, wives, and their respective parents. In general, there are two potential costs of marital discord initiated by the husband, the direct cost to the wife and the external cost to the family, i.e., the disgrace. Parents care about the first cost only insofar as they are altruistic toward their daughters. Thus, to the extent that the second cost is important, altruism towards daughters is not strictly necessary to explain watta satta.

Nor is it necessary that brothers display altruism toward their sisters. Husbands can be made to retaliate against their own wives for their brother-in-laws' misdeeds purely out of their own self-interest, not out of any direct concern for their sisters' well-being. It is the ability to withhold transfers, broadly construed, that gives parents leverage over their son, à la Becker's (1981) Rotten-Kid Theorem. As we explain later, obtaining similar leverage over their son-in-law is costly. 


\subsection{The Problem}

Once marriage has taken place, a husband's bargaining position vis à vis his wife vastly improves (in light of her virtually nonexistent exit options) and negotiations over the marital surplus are reopened. Suppose that a husband has the power to punish his wife if she does not agree to hand over an amount of surplus $B$. Carrying out this punishment imposes a cost $C$, which may, as already noted, be shared between the wife and her family. In a world of complete information, one might think that such punishment threats would never be carried out in equilibrium, but, as the literature on sanctions, strikes and related bargaining games has shown (Eaton and Engers, 1992; Fernandez and Glazer, 1991; Busch, et al. 1998), this is not the case. Equilibria exist in which a wife, in our context, may not immediately comply with her husband's demands and he may end up punishing her. While, generally speaking, the occurrence of such inefficiency depends on the relative costs and benefits to each of the principals, and on their respective degrees of impatience, the key point from our perspective is that, ex-ante, all marriages are potentially inefficient. ${ }^{8}$

Consider, then, two sets of parents $i=a, b$ each with exactly one married son and one married daughter. The sons receive a transfer of size $T>B$. Let $\sigma_{i}=1$ when the son of parent $i$ makes (and carries out) the punishment threat and $\sigma_{i}=0$ when he does not, and let $\sigma_{i}^{\prime}$ be the corresponding indicator for the son-in-law of parent $i$. Parents effectively control the choice of $\sigma_{i}$ because the son knows that his transfer will be reduced by more than $B$ if punishing his wife makes them worse off. Therefore, to analyze the wife punishment decision, it is sufficient to examine the payoff function of the parents, $v_{i}\left(\sigma_{i}, \sigma_{i}^{\prime}\right)$.

Clearly, $v_{i}(1,0)>v_{i}(0,0)$, because the son gains $B$ at no cost to himself or to his parents; the parents share in this gain by reducing transfers to the son by an amount less than $B$. Likewise, $v_{i}(1,1)>v_{i}(0,1)$. But how does $v_{i}(1,1)$ compare to $v_{i}(0,0)$ ? Begin with the case in which parents do not care about their daughter's utility. When $\sigma_{i}=\sigma_{i}^{\prime}=1$, there is a benefit accruing to the son, some of which is skimmed off by the parents, and a cost $C$ imposed by the son-in-law, some of which is borne by the parents. If the cost to the parents exceeds the benefit, then $v_{i}(0,0)>v_{i}(1,1)$. So, if parents are neither altruistic toward their daughters nor share in her disgrace from being punished, then they have no motive to restrain their son or son-in-law.

\footnotetext{
${ }^{8} \mathrm{An}$ alternative source of marital inefficiency is incomplete information. For example, the wife may not know ex-ante whether or not her husband is the 'type' who would be willing to carry out his threat. A husband may, therefore, need to punish his wife as a way of signalling his type (see Bloch and Rao, 2002 , for a related model).
} 
The situation is different when parents are altruistic toward their daughters. Suppose that at the time of her marriage, parents make transfers to their daughter (e.g., in the form of dowry) so that the parents' marginal rate of substitution between son's and daughter's utility is -1 . Under $\sigma_{i}=\sigma_{i}^{\prime}=1$, the son gains $B$ ex-post but the daughter loses $B$ plus her share of $C$. Since this effectively lowers the overall amount of resources available to their children, parents must be worse off (irrespective of whether they can make compensatory transfers to their daughter once she is married). With altruism toward daughters, therefore, even if parents bear no direct cost of their son-in-laws misdeeds (i.e., their share of $C$ is zero $), v_{i}(0,0)$ must exceed $v_{i}(1,1)$.

Given the payoff ordering: $v_{i}(1,0)>v_{i}(0,0)>v_{i}(1,1)>v_{i}(0,1)$, a no-punishment equilibrium would be preferred by both sets of parents to a punishment equilibrium. The problem is how to coordinate the actions of the parents to achieve this result. In the absence of coordination, it will be in the interest of each set of parents to allow their sons to punish their wives.

\subsection{Rationalizing Exchange Marriage}

An exchange marriage solves this coordination failure by forging a strategic link between the two sets of parents. Specifically, we now have $\sigma_{a}=\sigma_{b}^{\prime}$ and $\sigma_{b}=\sigma_{a}^{\prime}$ because the sonin-law of parent $a$ is the son of parent $b$ and vice-versa. This fact leads to the following game between the two sets of parents in normal form

\begin{tabular}{ccc} 
& \multicolumn{2}{c}{ Parent $a$} \\
\cline { 2 - 3 } Parent $b$ & $\sigma_{a}=1$ & $\sigma_{a}=0$ \\
\hline$\sigma_{b}=1$ & $v_{a}(1,1), v_{b}(1,1)$ & $v_{a}(0,1), v_{b}(1,0)$ \\
$\sigma_{b}=0$ & $v_{a}(1,0), v_{b}(0,1)$ & $v_{a}(0,0), v_{b}(0,0)$ \\
\hline
\end{tabular}

Given the payoff structure already discussed, this game is none other than the Prisoner's Dilemma. Since it is presumably being played repeatedly for an unknown duration, it is not unreasonable to suppose that the two sets of parents will achieve the cooperative solution $\left(\sigma_{a}, \sigma_{b}\right)=(0,0)$. For example, we can imagine a 'tit-for-tat' equilibrium in which a deviation by one set of parents is (credibly) punished by the other set of parents temporarily 'unleashing' their own son; i.e., pressuring him using the stick of withdrawing transfers to punish his wife. A husband's malfeasance is thus deterred in equilibrium by the threat that his brother-in-law will retaliate in-kind against his sister.

The difference between watta satta and conventional marriage should now be clear. 
The marriage of a son to a son-in-law's sister establishes reciprocity. In a non-exchange marriage, parents have no way to retaliate in-kind if their son-in-law punishes their daughter because their son is married to someone else's sister. This yields an empirically testable hypothesis: Marital inefficiency or discord is less likely to occur in a watta satta marriage as compared to a conventional marriage.

Watta satta is certainly not the only conceivable mechanism for restraining husbands, but it may be the cheapest and most reliable one in the context of rural Pakistan. One can imagine an arrangement, for example, whereby parents promise to make a lifetime stream of payments of value $B+\varepsilon$ to their son-in-law conditional on his continued good treatment of their daughter. ${ }^{9}$ In principle, such a scheme could obviate the lack of commitment by the son-in-law not to mistreat his wife, although, in the face of uncertainty, hold-up is always a possibility and the scheme could break down. Furthermore, maintaining their son-in-law's good behavior entails a real resource cost to the parents of $B+\varepsilon$, one which is not present under watta satta. ${ }^{10}$ This is not to suggest that watta satta is itself costless (as we emphasize in our conclusion), only that in an environment with generally low and variable incomes, lax legal enforcement, and strong codes of family honor, this institution may be the most effective means available to prevent marital discord.

\section{Empirical Strategy}

The decision to undertake a watta satta marriage depends on each side's ability to do so (about which more will be said in the next subsection) and its willingness to do so. Aside from the benefits already discussed, willingness is a function of a host of personal and cultural factors, some of which could influence behavior within the marriage itself. For example, traditional practices like watta satta may be more prevalent in households where women would otherwise have low status and thus be treated badly by their husbands. Parents might also be more inclined to arrange a watta marriage for a son prone to

\footnotetext{
${ }^{9}$ As an empirical matter, monetary transfers between the wife's natal family and her husband's household are rare; only $14 \%$ of women in our sample report that their parents ever provided such support during their marriage for any reason.

${ }^{10}$ The argument is actually more complicated than this because the parents are assumed to have a son in an identical situation, i.e., also receiving a payment from his in-laws. Under the assumptions of the Rotten-Kid Theorem, the parents will share these gains with their son by reducing transfers to him, effectively taxing his extra wealth at a rate $\tau$. For a given payment $P$, as soon as $(1-\tau) P$ falls below $B$, the son will no longer have an incentive to restrain himself. Thus $(1-\tau) P=B+\varepsilon$. Since each set of parents must pay out $P$ to their son-in-law while receiving $\tau P$ in 'revenue' from their own son, the net cost of the scheme to them is $(1-\tau) P$, which is $B+\varepsilon$.
} 
violence in the first place, since he could be better counted on to mete out retaliation. In short, there is likely to be selection into watta satta according to unobservables that determine marital discord. Indeed, similar arguments apply to a whole range of features of the marriage: age at marriage (and, by implication, school attainment), the age difference and kinship relation between husband and wife, transfers at the time of marriage, and so on, all of which are potentially endogenous with respect to marital outcomes.

With this in mind, we propose a simultaneous bivariate model of the form

$$
\begin{gathered}
y_{i}=1\left(\alpha W S_{i}+\beta^{\prime} z_{1 i}+\omega^{\prime} x_{i}+e_{i}>0\right) \\
W S_{i}=1\left(\gamma^{\prime} z_{1 i}+\delta^{\prime} z_{2 i}+\varphi^{\prime} x_{i}+u_{i}>0\right)
\end{gathered}
$$

where $y_{i}$ is the binary marital discord indicator for woman $i, x_{i}$ is a vector of exogenous controls, and $e_{i}$ and $u_{i}$ are error terms that are, in general, correlated with each other. The remaining variables, $z_{1 i}$ and $z_{2 i}$, are better understood in the context of our identification strategy, to which we turn next.

\subsection{Identification}

Semiparametric identification of the watta satta effect $\alpha$ requires an exclusion restriction from equation 1. We use information on the number, age, and sex composition of the woman's siblings at the time of her marriage. The logic is straightforward: the ability of a family to arrange a watta satta for their daughter depends on the available supply of counterpart grooms. As we have seen, the great majority of exchange marriages in rural Pakistan involve brothers and sisters. In two-child families, only those with one boy and one girl can contemplate a brother-sister watta. Thus, only half of all twochild families are, to borrow a term from the program evaluation literature, 'eligible' for exchange marriage. More generally, the probability of watta satta for a daughter is increasing in the number of sons relative to daughters. In addition, because girls typically marry young in rural Pakistan (the median age at marriage is 17 in our sample), and grooms are generally older than brides (median age gap is 4 years), having an older brother, but not too much older, increases the likelihood of the woman entering watta satta relative to having any kind of brother. Likewise, a woman's sisters, particularly older ones not too far away in age, will be in competition with her for an available brother to form a watta, so that the probability of such an arrangement declines as the number of close-older sisters increases. 
Excluding such demographic variables from the second-stage equation 1 may be problematic to the extent that family size and sex composition is subject to parental control. While the cohort of individuals we consider were all born well before selective abortion became widespread in South Asia (albeit never in rural Pakistan), other forms of sex selection have long been available, such as fertility stopping rules and underinvestment in girls' health care and nutrition. The number of brothers and sisters a woman has may thus depend on the intensity of boy-preference on the part of her parents. Furthermore, parents exhibiting stronger boy-preference may also choose to reallocate more household resources away from (surviving) girls to boys along various dimensions; e.g., by discriminating in schooling and/or nutrition, and, more relevant to the present discussion, by expending less effort on preventing their daughter's maltreatment within her marriage. In particular, such parents might take less care in choosing a 'good' husband ex-ante or may monitor their daughter's treatment in her husband's household less assiduously ex-post.

To capture possible correlation between natal family boy-preference and marital discord, we include $z_{1 i}=\left\{B_{i}, S_{i}\right\}$ directly in equation 1 , where $B_{i}$ and $S_{i}$ represent the total number of woman $i$ 's brothers and sisters, respectively. Excluded from the second stage is $z_{2 i}=\left\{B_{i}^{[0,5]}, S_{i}^{[0,5]}\right\}$, the number of brothers and sisters $0-5$ years older than woman $i$. In other words, $\alpha$ is identified off of variation in the relative number of brothers and sisters that fall in the five year interval preceding the birth of the woman in question. Including $z_{1 i}$ in equation 1 deals with differential female mortality, in that women whose parents have stronger boy-preference would, in this event, have fewer sisters. Less obviously, our strategy also handles sex-specific stopping rules. Specifically, suppose that parents continue to bear children until they have $M_{i}$ boys, where population variation in $M_{i}$ reflects heterogeneity in boy-preference. If a male is born with probability 0.5 , then a woman is expected to have $2 M_{i}+1$ siblings (see Yamaguchi, 1989). Therefore, $M_{i}$ may be expressed as $0.5\left(B_{i}+S_{i}-1\right)$ plus error due to the randomness of child gender. Sibling cohort size is, consequently, a good proxy for boy-preference heterogeneity. ${ }^{11,12}$

\footnotetext{
${ }^{11}$ Note that, along with $B_{i}+S_{i}$, we are also implicitly controlling for the proportion of boys among children in the natal family. According to the calculations of Yamaguchi (1989), however, for $M_{i}>1$ the expected proportion of boys falls rather slowly as $M_{i}$ increases. Therefore, this proportion is likely to be a poor proxy for boy-preference in rural Pakistan.

${ }^{12}$ One might think that, for a given $B_{i}+S_{i}$, a woman having an older brother must have had parents with lower boy-preference, since they continued bearing children after having a boy. This statement is only true under the very special assumptions that (a) some families exhibit no sex-specific stopping behavior whatsoever and that (b) all families with a boy-preference have $M_{i}=1$, in which case not stopping after a boy implies that a family is of the first type. However, under the far more plausible assumption (especially in the context of rural Pakistan) that $M_{i}>0$ for all families, not stopping after a boy indicates a desire
} 
If unobserved determinants of marital discord and of the natal family's fertility choices turn out not to be correlated, then including $z_{1 i}$ in equation 1 is a waste of identifying information, reducing the efficiency of the selectivity corrected estimates. For this reason, we will test down to the most parsimonious specification of equation 1 , with respect to $z_{1 i}$, that is not rejected by the data.

\section{Results}

\subsection{Preliminary Analysis}

The first three columns of Table 2 report univariate probit results for our indicators of marital discord: estrangement, domestic abuse, and depression. In these specifications, we simply ignore selection into watta satta marriages. Each probit includes a cubic polynomial in woman's age, her father's education level (completed primary, completed secondary or higher), a dummy for whether her father owned land at the time of her marriage, and dummies for district of residence. Watta satta has no significant impact on any of the discord indicators; as already pointed out, however, selectivity might make outcomes for women in watta satta marriages appear worse than they really are.

The fourth column of Table 2 presents univariate probit estimates of our 'first-stage' equation 2. With respect to instrument relevance, the older-close brother and sister variables in $z_{2 i}$ are highly jointly significant conditional on the total numbers of male and female siblings $\left(\chi_{(2)}^{2}=26.1 ; p\right.$-value $\left.<0.0000\right)$. Moreover, the sign patterns of the coefficients make sense: having more brothers (sisters) raises (lowers) the probability that a woman is in a watta satta marriage. Also notable is that fathers with secondary education are significantly less likely to arrange exchange marriages for their daughters (since fewer than $4 \%$ of mothers had ever attended school, we do not include corresponding dummies for mother's education), although there are no such difference by land ownership. To the extent that father's education is an important indicator of status, watta satta seems to be more prevalent among low status households.

\subsection{Main Findings}

Before turning to the selectivity-corrected results, a word about the choice of estimation method. Instead of assuming joint normality and estimating a bivariate probit, we model

for even more boys. Moreover, for a woman arbitrarily chosen from the birth order, the fact of her having an older brother conveys no information about $M_{i}$, conditional on $B_{i}+S_{i}$. 
the joint distribution of the error terms $\left(e_{i}, u_{i}\right)$ nonparametrically using a discrete factor approximation (e.g., Heckman and Singer, 1984, Altonji, et al. 2005). ${ }^{13}$ Relaxing the normality assumption is a way of ensuring that identification of $\alpha$ is coming off of the exclusion restrictions laid out above and not the particular form of the bivariate normal distribution. Alternatively, one could avoid distributional assumptions by estimating a linear probability model using 2SLS, but this estimator can be far less efficient than a bivariate probability model. ${ }^{14}$

Tables 3 presents the results of the semiparametric bivariate probability model estimation for the three marital discord indicators. Only selected coefficients of the latent index in equation 1 are reported. Specification (1) includes the full vector $z_{1 i}$ in the second stage, whereas specification (2) eliminates the elements of $z_{1 i}$ with insignificant coefficients, but retains them in the first stage. The main result is consistent across all three of the indicators: Inefficiency is significantly less likely to occur in watta satta marriages than in conventional marriage. Comparing these estimates to their counterparts in Table 2, we see that there is indeed negative selection into watta satta marriages; i.e., women who would otherwise be more likely to be estranged, beaten by their husbands, or depressed tend to end up in such arrangements.

There are salient differences across the indicators of marital discord. Statistically speaking, the evidence for a watta satta effect on the probability of estrangement is much stronger than for domestic abuse and depression, although the relative marginal effects evaluated at the means are not that far apart: watta satta reduces the odds of estrangement by $65 \%$, domestic abuse by $46 \%$, and major depression by $56 \%$ (based on specifications (2)). Only in the case of domestic abuse does the woman's sibling cohort composition, specifically her number of brothers, have a direct impact on marital discord. Otherwise, we cannot reject the hypothesis that these variables are excludable from the second stage. When these restrictions are imposed in specification (2), the standard errors fall but the estimates of $\alpha$ change neither substantially nor in a consistent direction.

\footnotetext{
${ }^{13}$ Specifically, we let $e_{i}=\rho_{e} \mu+\varepsilon_{i}$ and $u_{i}=\rho_{u} \mu+\nu_{i}$ where $\rho_{e}$ and $\rho_{u}$ are factor loadings, $\mu$ is a discrete random effect, and $\varepsilon_{i}$ and $\nu_{i}$ are independent normal disturbances. After suitable normalization, the parameters of the distribution of the discrete random effect (the points of support of $\mu$ and their associated probabilities), the factor loadings, and the model coefficients are estimated jointly by maximum likelihood. Three points of support were sufficient for all the indicators but depression, for which only two points could be fit. Also, in no case could we reject the hypothesis that $\rho_{e}=\rho_{u}$, so this restriction is maintained throughout.

${ }^{14}$ In practice, all of these estimators - semiparametric bivariate probability, bivariate probit, and twostage linear probability - lead to similar conclusions, although, as expected, the precision of the estimates varies considerably. Generally, relative precision is highest for the bivariate probit and lowest for the linear probability, with the estimates from the semiparametric model falling somewhere in between.
} 
Up to now, we have resisted the temptation to control for potentially endogenous characteristics of the woman or her marriage, other than her watta satta status. However, given the importance of endogamy and its possible confounding effects as far as watta satta is concerned, we make an exception in this case. Specification (3) of Tables 3 thus controls for a woman's relationship to her husband (blood relative, fellow zaat/biraderi member) as well as her proximity to her natal family. As noted, watta satta is considerably more prevalent in marriages among relatives, but there is no evidence that this is what is driving our findings. Subject to the caveat that we are treating the relation between spouses as exogenous, the watta satta effect is not attributable to cousin-marriage. Marrying a relative seems to reduce the incidence of domestic abuse, but even here a significant impact of watta satta remains. The wife's proximity to her natal family, meanwhile, has the largest impact on the probability of estrangement, which makes sense given that greater proximity lowers her cost of a temporary return home. But the inclusion of this variable does nothing to diminish the estimated impact of watta satta.

\section{Conclusion}

We began with the idea that, in a setting where husbands wield considerable coercive power that is costly to check ex-post, forms of marriage should adapt to protect the interests of women and their families. In this light, we have shown that a bride exchange accompanied by mutual retaliatory threats could be a mechanism to coordinate the actions of two sets of in-laws, each of whom wish to restrain their son-in-laws but who only have the ability to restrain their sons. Our empirical results support this view. The likelihood of marital discord is indeed lower in watta satta arrangements as compared to conventional marriages. This result emerges most strongly in the case of estrangement, the clearest and most publicly observable expression of marital discord. But we also find that watta satta significantly reduces the probability of domestic abuse and of major depressive episodes. Since freedom from abuse and depression is undoubtedly a benefit, watta satta is clearly in women's interest, regardless of whether the institution is ultimately motivated by parents' altruism toward their daughters or by their desire to maintain family honor. ${ }^{15}$

Watta satta is obviously not a first-best solution to the problems inherent in the

\footnotetext{
${ }^{15}$ One qualification is that some of the 'rents' accruing to women whose families are able to arrange a watta satta marriage may be appropriated by their brothers via a reallocation of parental transfers in favor of sons. Even if utility were perfectly transferable, however, women in watta-eligible familes would still share in the overall wealth effect.
} 
incompleteness of the marriage contract. Restricting the set of spouses for a pair of siblings to come from the same family severely circumscribes the choice of mates, which may reduce the average quality of marital matches. This type of cost may give us a clue as to why watta satta is so pervasive in rural Pakistan. Given the already high degree of endogamy, by family, caste, and village, the marginal restriction on marital choice imposed by watta satta might have only a negligible affect on average match quality. ${ }^{16}$ Ultimately, of course, we would like to model the extent of endogamy itself, but this must remain a topic for future research.

\footnotetext{
${ }^{16}$ The contrast between south and north India is suggestive in this regard. Sibling exchange is common in the south, where cross-cousin marriage and village/clan endogamy are also the norm, but is nearly absent in the north, where the idealized form of marrriage (kanyadana) strongly proscribes cross-cousin marriage and village/clan endogamy (Trautman, 1993).
} 


\section{References}

[1] Altonji, J., T. Elder and C. Taber, 2005. "Selection on observed and unobserved variables: Assessing the effectiveness of catholic schools," J.P.E., 113(1): 151-84.

[2] Becker, G. 1981. A Treatise on the Family. Cambridge, Mass.: Harvard Univ. Press.

[3] Bloch, F. and V. Rao, 2002. "Terror as a bargaining instrument: A case study of dowry violence in rural India," A.E.R., 92(4):1029-43.

[4] Bohannan, L. 1949. "Dahomean marriage: A revaluation," Africa: J. of the International African Institute, 19(4): 273-87.

[5] Botticini, M. and A. Siow, 2003. "Why dowries?" A.E.R., 93(4): 1385-98.

[6] Busch, L.-A., S. Shi, and Q. Wen, 1998. "Bargaining with surplus destruction," Canadian Journal of Economics, 31(4):915-932.

[7] Eaton, J. and M. Engers, 1992. "Sanctions," J.P.E., 100(5):899-928.

[8] Edlund, L. 1999. "Son preferences, sex ratios, and marriage patterns," J.P.E., 107(6) pt. 1: $1275-1304$.

[9] Fernandez, R. and J. Glazer, 1991. "Striking for a bargain between two completely informed agents," A.E.R., 81(1):240-52.

[10] Greif, A. 1993. "Contract enforceability and economic institutions in early trade: The Maghribi trader's coalition," A.E.R., 83(3):525-48.

[11] Heckman, J. and B. Singer, 1984. "A method for minimizing the impact of distributional assumptions in econometric models for duration data," Econometrica, 52(2): 271-320.

[12] Karve, I. 1993. "The kinship map of India,' in Family, Kinship and Marriage in India (ed.) P. Uberoi, Oxford University Press.

[13] La Ferrara, E. 2003. "Kin groups and reciprocity: A model of credit transactions in Ghana," A.E.R., 93(5):1730-51.

[14] Lundberg, S. and R. Pollack, 1993. "Separate spheres bargaining and the marriage market," J.P.E., 101(6):998-1010. 
[15] Manser, M. and M. Brown, 1980. "Marriage and household decision-making: A bargaining analysis," International Economic Review, 21(1):31-44.

[16] McElroy, M. and M. Horney, 1981. "Nash-bargained decisions: Toward a generalization of the theory of demand," 22(2):333-49.

[17] Meek, C. 1936. "Marriage by exchange in Nigeria: A disappearing institution," Journal of the International African Institute, 9(1):64-74.

[18] Mencher, J. and H. Goldberg, 1967. "Kinship and marriage regulations among the Namboodiri Brahmans of Kerala," Man, 2(1): 87-106.

[19] North, D. and B. Weingast, 1989. "Constitutions and commitment: The evolution of institutions governing public choice in seventeenth century England," J. of Economic History, 49(Dec.):803-32.

[20] Rose, H. 1908. "Hindu betrothal observances in the Punjab," The Journal of the Royal Anthropological Institute of Great Britain and Ireland, 38(Jul.-Dec.):409-18.

[21] Trautmann, T. R. 1993. "Marriage rules and patterns of marriage in the Dravidian kinship region,' in Family, Kinship and Marriage in India (ed.) P. Uberoi, Oxford University Press.

[22] Williamson, O., 1983. "Credible Commitments: Using Hostages to Support Exchange," A.E.R., 73(4): 519-40.

[23] World Bank. 2005. "Family law and custom in Pakistan," in Bridging the Gender Gap: Opportunities and Challenges (Pakistan Country Gender Assessment), Environment and Social Development Sector Unit, South Asia Region, Washington D.C.

[24] Yamaguchi, K., 1989. "A formal theory for male-preferring stopping rules of childbearing: Sex differences in birth order and in the number of siblings," Demography, 26(3): 451-65.

[25] Zhang, J. and W. Chan. 1999. "Dowry and wife's welfare: A theoretical and empirical analysis," J.P.E., 107(4):786-808.

[26] Zhang, W. 2000. "Dynamics of marriage change in Chinese rural society in transition: A study of a northern Chinese village," Population Studies, 54:57-69. 


\section{Table 1: Concordance Tests on Sister-in-law Pairs}

\begin{tabular}{lccc}
\hline Marital Outcome & $p$-value $^{\mathbf{a}}$ & $\begin{array}{c}\text { Additional } \\
\text { controls }\end{array}$ & $\begin{array}{c}\text { No. of sister- } \\
\text { in-law pairs }\end{array}$ \\
\hline $\begin{array}{l}\text { Ever been estranged from husband } \\
\text { Ever been estranged from husband }\end{array}$ & 0.007 & $\Delta m, \Delta m^{2}, \Delta m^{3}$ & 515 \\
& 0.010 & $\Delta m, \Delta m^{2}, \Delta m^{3}$, & 515 \\
Log(months of last estrangement) & 0.005 & $r, r \times y^{s}$ & 50 \\
$\begin{array}{l}\text { Ever been physically abused by husband } \\
\begin{array}{l}\text { Episode of major depression in last 12 } \\
\text { months }\end{array}\end{array}$ & 0.278 & $\Delta m, \Delta m^{2}, \Delta m^{3}$ & 518 \\
\hline
\end{tabular}

a One sided t-test on coefficient $\theta_{3}$, as described in the text.

b

b All regressions include the sister-in-law's outcome $\left(y^{s}\right)$, the watta satta indicator and the interaction between these two variables; $m$ denotes years of marriage, $\Delta$ the difference across sister-in-laws, and $r$ is a dummy for the whether the husband and wife are blood relatives. 
Table 2: Univariate Probit Estimates

\begin{tabular}{|c|c|c|c|c|c|}
\hline Independent variables & $\begin{array}{c}\text { Mean } \\
\text { (St. Dev.) }\end{array}$ & $\begin{array}{c}\text { (1) } \\
\text { Ever Been } \\
\text { Estranged }\end{array}$ & $\begin{array}{c}(2) \\
\text { Physical } \\
\text { Abuse }\end{array}$ & $\begin{array}{c}(3) \\
\text { MD Last } \\
12 \text { Mo. }\end{array}$ & $\begin{array}{c}(4) \\
\text { Watta } \\
\text { Satta }\end{array}$ \\
\hline Watta satta (WS) & 0.36 & $\begin{array}{c}0.097 \\
(0.068) \\
{[0.153]}\end{array}$ & $\begin{array}{c}0.005 \\
(0.062) \\
{[0.935]}\end{array}$ & $\begin{array}{l}-0.067 \\
(0.059) \\
{[0.255]}\end{array}$ & --- \\
\hline $\begin{array}{l}\text { Number of older brothers } \\
\text { within } 5 \text { years of woman } \\
\text { at time of marriage }\end{array}$ & $\begin{array}{c}0.91 \\
(1.12)\end{array}$ & --- & --- & --- & $\begin{array}{l}0.149 \\
(0.030) \\
{[0.000]}\end{array}$ \\
\hline $\begin{array}{l}\text { Number of older sisters } \\
\text { within } 5 \text { years of woman } \\
\text { at time of marriage }\end{array}$ & $\begin{array}{c}0.80 \\
(1.01)\end{array}$ & --- & --- & --- & $\begin{array}{l}-0.074 \\
(0.029) \\
{[0.012]}\end{array}$ \\
\hline $\begin{array}{l}\text { Number of brothers } \\
\text { at time of marriage }\end{array}$ & $\begin{array}{c}2.93 \\
(1.74)\end{array}$ & --- & --- & --- & $\begin{array}{l}0.105 \\
(0.017) \\
{[0.000]}\end{array}$ \\
\hline $\begin{array}{l}\text { Number of sisters } \\
\text { at time of marriage }\end{array}$ & $\begin{array}{c}2.77 \\
(1.77)\end{array}$ & --- & --- & --- & $\begin{array}{l}-0.062 \\
(0.016) \\
{[0.000]}\end{array}$ \\
\hline $\begin{array}{l}\text { Father completed primary } \\
\text { school only }\end{array}$ & 0.19 & $\begin{array}{c}0.039 \\
(0.068) \\
{[0.565]}\end{array}$ & $\begin{array}{c}0.084 \\
(0.072) \\
{[0.242]}\end{array}$ & $\begin{array}{c}0.112 \\
(0.068) \\
{[0.099]}\end{array}$ & $\begin{array}{l}-0.140 \\
(0.074) \\
{[0.061]}\end{array}$ \\
\hline $\begin{array}{l}\text { Father completed secondary } \\
\text { school or above }\end{array}$ & 0.13 & $\begin{array}{l}-0.220 \\
(0.093) \\
{[0.019]}\end{array}$ & $\begin{array}{l}-0.226 \\
(0.108) \\
{[0.036]}\end{array}$ & $\begin{array}{l}-0.074 \\
(0.085) \\
{[0.384]}\end{array}$ & $\begin{array}{l}-0.406 \\
(0.089) \\
{[0.000]}\end{array}$ \\
\hline $\begin{array}{l}\text { Father owned land } \\
\text { at time of marriage }\end{array}$ & 0.40 & $\begin{array}{l}-0.034 \\
(0.059) \\
{[0.563]} \\
\end{array}$ & $\begin{array}{l}-0.135 \\
(0.056) \\
{[0.016]} \\
\end{array}$ & $\begin{array}{l}-0.005 \\
(0.054) \\
{[0.924]}\end{array}$ & $\begin{array}{l}-0.014 \\
(0.056) \\
{[0.797]} \\
\end{array}$ \\
\hline Estimation sample & 3101 & 3079 & 3095 & 3101 & 3101 \\
\hline
\end{tabular}


Table 3: Semiparametric Bivariate Probability Model Estimates

\begin{tabular}{|c|c|c|c|c|c|c|c|c|c|}
\hline \multirow[b]{2}{*}{ Independent variables } & \multicolumn{3}{|c|}{ Ever Been Estranged } & \multicolumn{3}{|c|}{ Ever Been Physically Abused } & \multicolumn{3}{|c|}{ Depression Last 12 Months } \\
\hline & (1) & (2) & (3) & (1) & (2) & (3) & (1) & (2) & (3) \\
\hline Watta satta (WS) & $(0.276)$ & $(0.254)$ & $(0.454)$ & $(0.193)$ & $(0.187)$ & $(0.204)$ & $(0.350)$ & $(0.298)$ & $(0.302)$ \\
\hline \multirow{2}{*}{$\begin{array}{l}\text { Number of brothers at time of } \\
\text { marriage }\end{array}$} & 0.048 & --- & --- & 0.048 & 0.055 & 0.056 & -0.004 & --- & --- \\
\hline & $(0.029)$ & & & $(0.020)$ & $(0.020)$ & $(0.020)$ & $(0.021)$ & & \\
\hline \multirow{3}{*}{$\begin{array}{l}\text { Number of sisters at time of } \\
\text { marriage }\end{array}$} & -0.021 & --- & --- & 0.025 & --- & --- & 0.007 & --- & --- \\
\hline & $(0.025)$ & & & $(0.016)$ & & & $(0.020)$ & & \\
\hline & [0.398] & & & {$[0.107]$} & & & [0.739] & & \\
\hline \multirow{2}{*}{$\begin{array}{l}\text { Natal family resides in same or } \\
\text { neighboring village }\end{array}$} & --- & --- & 0.398 & --- & --- & 0.097 & --- & --- & 0.186 \\
\hline & & & $(0.144)$ & & & $(0.084)$ & & & $(0.091)$ \\
\hline \multirow{2}{*}{ Husband is blood relative } & & & $(0.187)$ & & & $(0.115)$ & & & $(0.116)$ \\
\hline & & & {$[0.353]$} & & & [0.009] & & & [0.932] \\
\hline \multirow{3}{*}{$\begin{array}{l}\text { Husband is fellow zaat/biraderi } \\
\text { member }\end{array}$} & --- & --- & 0.305 & --- & --- & -0.152 & --- & --- & 0.094 \\
\hline & & & $(0.231)$ & & & $(0.141)$ & & & $(0.130)$ \\
\hline & & & [0.188] & & & {$[0.282]$} & & & $(0.470)$ \\
\hline Log likelihood & -3108.6 & -3110.6 & -3068.5 & -3197.9 & -3198.9 & -3153.4 & -3323.0 & -3323.1 & -3282.6 \\
\hline
\end{tabular}

